\title{
Plasma Surface Treatment of BOPP Film by Dielectric Barrier Glow Discharge in Argon/Air
}

\author{
Longxi Chen ${ }^{1,2 *}$, Xiangjia Meng1,2, Zhen Mei1,2 \\ ${ }^{1}$ School of Information Engineering, Shandong Youth University of Political Science, Jinan, China \\ ${ }^{2}$ Key Laboratory of Information Security and Intelligent Control in Universities of Shandong, Jinan, China \\ Email: "clx@sdyu.edu.cn
}

Received 19 October 2015; accepted 10 November 2015; published 13 November 2015

Copyright (C) 2015 by authors and Scientific Research Publishing Inc.

This work is licensed under the Creative Commons Attribution International License (CC BY). http://creativecommons.org/licenses/by/4.0/

(c) (i) 0pen Access

\begin{abstract}
A plasma surface treatment of biaxially oriented polypropylene (BOPP) film was carried out with dielectric barrier glow discharge (DBGD) in Ar/air. The paper studied the effects of the ratios of Ar/air plasma on the BOPP surface modification. The results indicated that the efficiency of the plasma surface modification was improved with increasing treatment time and power density with DBGD in Ar/air. The water contact angle increased first and then decreased with the increase of the Ar/air mixture rate. The DBGD gives a better surface modification than filament discharge. The ageing behavior was influenced by the mixture rate of Ar/air, but the water contact angle of the treated sample was always less than that of un-treated sample.
\end{abstract}

\section{Keywords}

\section{Argon/Air, DBGD, BOPP, Surface Modification}

\section{Introduction}

Biaxially oriented polypropylene (BOPP) film is widely used as packaging materials, book covers, and a variety of containers. However, it is a kind of typical hard stick material because of its poor surface wettability, which limits its application in the field of industry [1] [2]. In order to improve the adhesion of the material, surface modification is needed. Chemical and physical processes have been developed to modify BOPP film, such as flame treatment, plasma treatment, ultraviolet treatment, metal plating, etching, oxidation, and surface grafting [3]-[8].

${ }^{*}$ Corresponding author. 
As a dry cleaning process, plasma treatment technology has a great market potential and an excellent application prospect [9]-[13]. The main advantage of plasma surface modification is that it can create active species at low temperature. There have been many researchers who use high-frequency corona discharge or low RF discharge for surface modification of BOPP. However, corona discharge is uneven, and the surface is easy to be damaged, which can lead to dents and pinholing on the surface. In DBGD, the products of the plasma pressure $p$ and the discharge gap $d$ are lower, so it is easier to form a uniform and stable plasma. The free electrons gain energy from an applied electric field; then the energy is transferred through collisions between the free electrons and the neutral molecules in the plasma. The transfer of energy leads to a host of reactive species; some of them become precursors for the plasma surface reaction. Therefore, plasma surface modification with DBGD is gaining more and more attention and research [14]-[20].

For plasma surface modification, the single gas is always used [2] [3] [21]-[27]. However, in general, the mixed gas and mixture ratio of the mixed gas can also have effects on the surface modification. In this paper, we carried out the plasma surface modification of BOPP film by DBGD in Ar/air. According to the analysis of the effects of air plasma, argon plasma and Ar/air plasma modification on the samples, the relationships between the material surface modification efficiency and discharge parameters, such as processing time, plasma pressure, and discharge power were given. Meanwhile, the effects of mixture rate of Ar/air on the surface modification of BOPP with fixed gas pressure and discharge power were studied. The paper was arranged as follows. In the following section, the experimental system and the experimental method were introduced. Then, the results and discussions were presented. Finally, the conclusions were given.

\section{Experimental}

\subsection{Experimental System}

The plasma surface treatment of BOPP film is carried out in a dielectric barrier glow discharge experiment system as shown in Figure 1. The experimental system consisted of two sets of power supply, the peak voltage of the AC power supply was 0 - $30 \mathrm{KV}$, the frequency region was $1 \mathrm{KHz}-100 \mathrm{KHz}$, and the power region is 0 $500 \mathrm{~W}$. The vacuum chamber was connected with two vacuum pumps, and a coupled electrode with insulated quartz glass slice was placed in the chamber, then the sample was put on the lower glass slice. The discharge gas was mixed with argon and air, and the purity of argon was 99.99\%. The waveforms of the discharge voltage and discharge current were measured by the digital oscilloscope (TDS 1012C-EDU), the photos were obtained by the digital camera (Canon PowerShot SX40-HS), the sample surface contact angle was measured by the Contact angle measuring instrument (JGW-360A), and the test liquid was distilled water and diiodomethane.

\subsection{Experimental Method}

The BOPP film was cut into $40 \mathrm{~mm} \times 30 \mathrm{~mm}$ rectangular pieces, and the pieces were cleaned in acetone solution for 12 hours, then the samples were rinsed with alcohol, finally the samples were put into the oven for drying 5 minutes. The vacuum chamber was pumped to a pressure of $0.1 \mathrm{~Pa}$, the mixed gas with air and argon flows into the reactor with a fixed mixture ratio. The inflow was stopped when the required pressure was achieved. The discharge parameters were adjusted according to different experimental environments, and the corresponding data were record. The samples were taken out from the vacuum chamber after the end of discharge, and the surface contact angle of the treated sample was measured by the contact angle measuring instrument (JGW-360A), the test liquid is distilled water. Three different positions of the sample surface were measured and the average values were calculated.

\section{Results and Discussion}

The diameter of the cross-section of the cylindrical vacuum chamber was about $390 \mathrm{~mm}$, the height was about $400 \mathrm{~mm}$, the discharge gap of DBGD could be adjusted according to the requirement of the experiments. In order to prevent the plasma deviating from the discharge gap to the exhaust port which connected to the vacuum chamber, a barrier metal mesh was applied to the port in the chamber. It was found that the discharge patterns were different with different pressures $p$ or different discharge gaps $d$. A glow discharge model with $p=0.3 \times$ $10^{5}$ pa and $d=5 \mathrm{~mm}$ was shown in Figure 2. The discharge voltage and discharge frequency are $10 \mathrm{KV}$ and 15 KHZ, respectively. The discharge frequency was measured by the digital oscilloscope, and the discharge voltage 


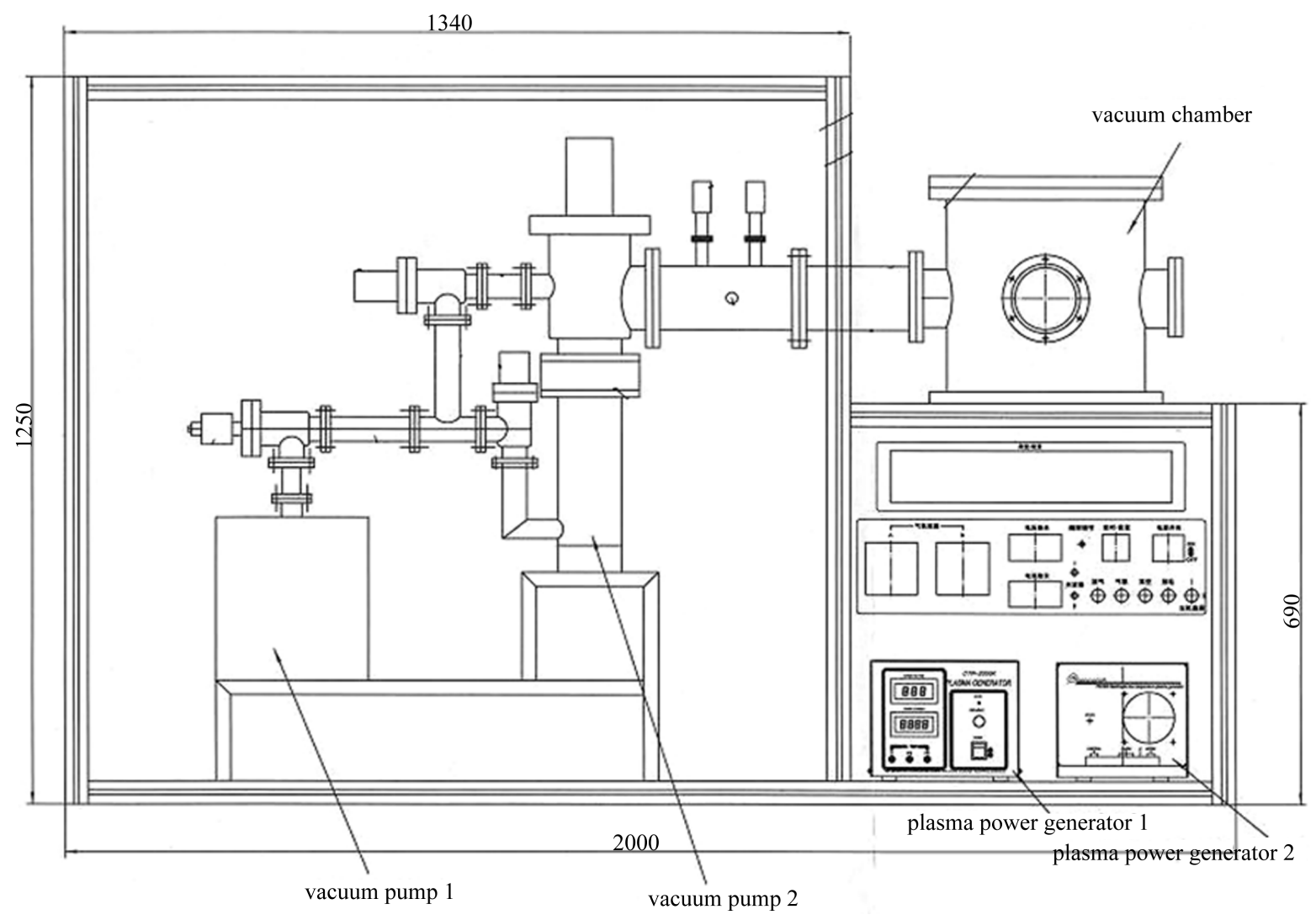

Figure 1. Schematic diagram of the experimental setup.

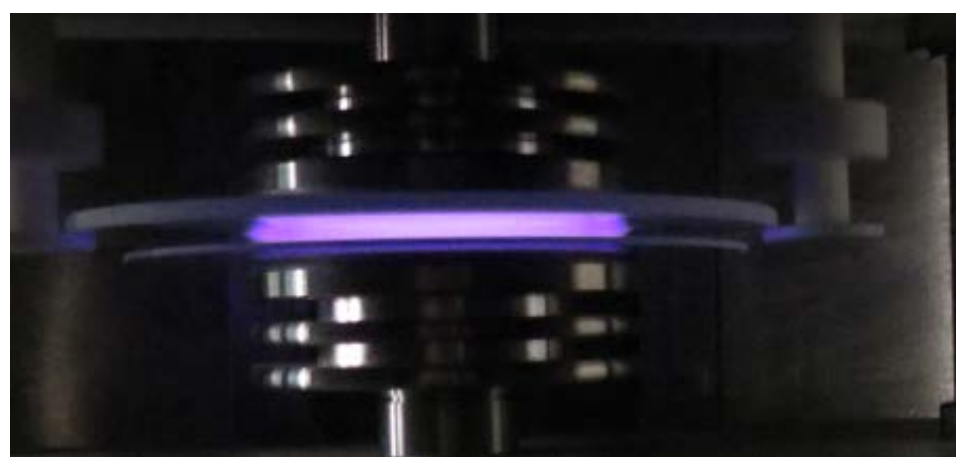

Figure 2. A snapshot of glow discharge pattern.

was characterized by measuring the resistance of the divider resistor. The ratio of Ar/air was 1:1. Figure 3 shows the waveforms of the discharge voltage and discharge current. It could be seen there was a strong current pulse in per half cycle, the peak of the waveforms appears in the same position in several periods.

In the experiment, the plasma surface treatment of BOPP film by DBGD in Ar/air were studied, and the effects of mixture ratio of Ar/air on the plasma surface modification of BOPP film were also analyzed. Given in Figure 4 were the diagrams of water contact angle with different plasma treatment time, the test liquid was distilled water. As can be seen from the figure, the surface modification by DBGD plasma was obvious. The contact angle of the BOPP surface became smaller with the increasing treatment time. It indicated that after Ar/air plasma treatment, the surface wettability of BOPP were greatly improved.

Figure 5 showed the $p_{r}$ for glow discharge with different discharge gaps $d$. It can be seen that the maximum pressure $p_{r}$ decreases with the increase of the discharge gaps $d$. The discharge gap was less than $1 \mathrm{~mm}$ for DBGD with one atmospheric pressure. In the following studies, Unless otherwise stated, we have discharge gap 


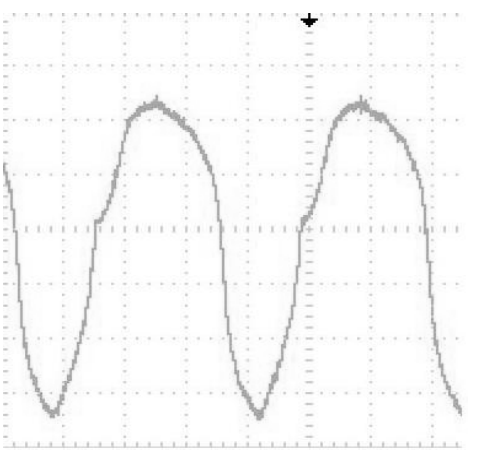

(a)

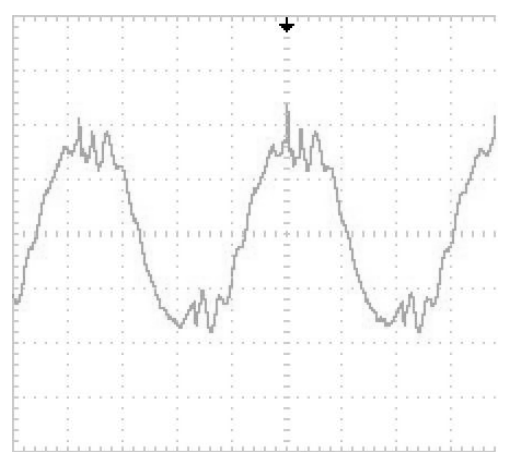

(b)

Figure 3. Voltage (a) and current (b) waveforms of glow discharge.

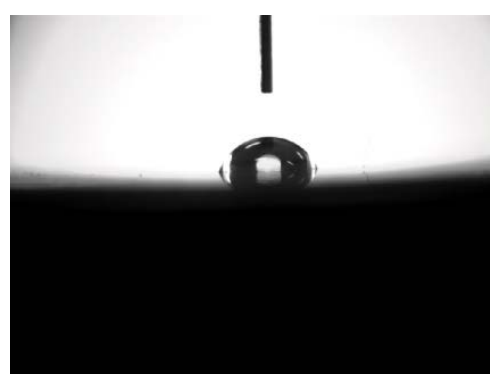

$\mathrm{t}=0$

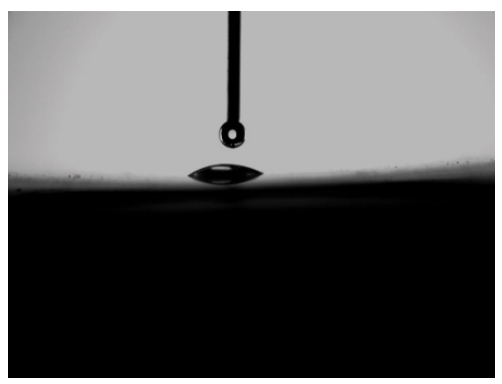

$\mathrm{t}=10 \mathrm{~s}$

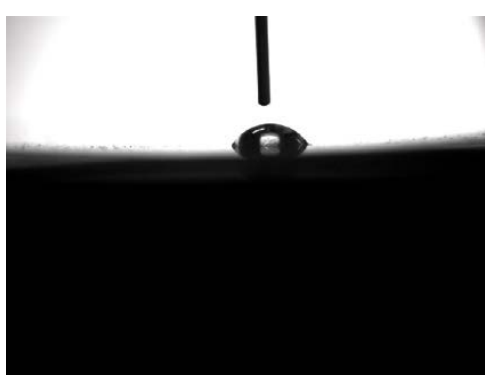

$\mathrm{t}=5 \mathrm{~s}$

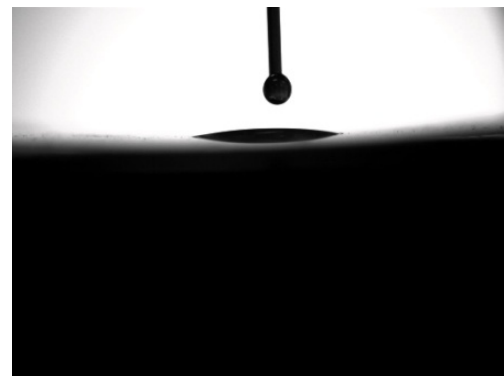

$\mathrm{t}=30 \mathrm{~s}$

Figure 4. The photos demonstrate the relationship between the water contact angle and glow discharge time.

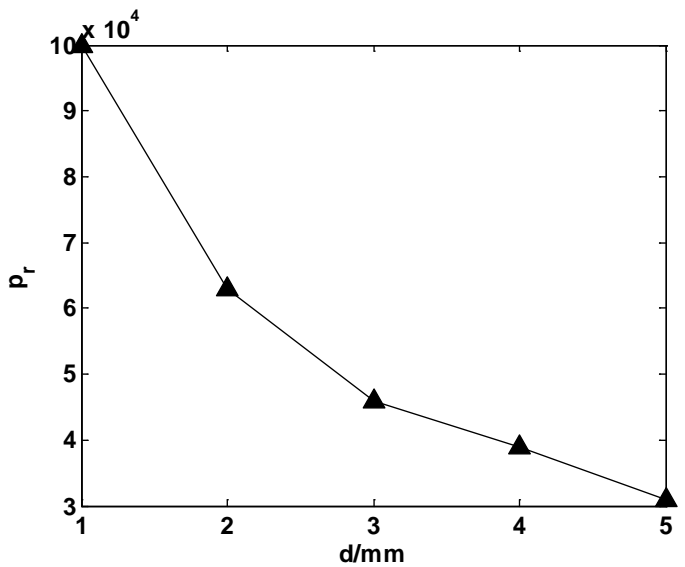

Figure 5. Dependence of the maximum pressure $p_{r}$ for glow discharge with different discharge gaps $d$. 
$d=5 \mathrm{~mm}$. Figure 6 gave the minimum glow discharge voltage versus the mixture ratio of Ar/air. The discharge voltage increased as the mixture ratio of Ar/air increased if the ratio below a critical value. That's because the quality of argon molecules is greater than the air molecules, it needs more energy in the ionization process. Above the critical mixture ratio, the discharge voltage very weakly increased with further increase of the mixture ratio, and the gas was nearly fully ionized.

In Figure 7, the changes of water contact angle with plasma treatment time were plotted. The discharge voltage was $10 \mathrm{KV}$, the discharge frequency is $15 \mathrm{kHz}$, and unless otherwise stated, we had the mixture ratio of Ar/air is 1:1. It was clearly found that the water contact angle decreased, but not linearly, with increasing treatment time. It indicated the hydrophilicity of BOPP film was well improved with DBGD plasma treatment. The contact angle was $81.9^{\circ}$ without plasma treatment, then the surface contact angle rapidly decreased to $11.7^{\circ}$ for $30 \mathrm{~s}$ plasma treatment. When the treatment time was more than $30 \mathrm{~s}$, the contact angle was almost unchanged with the increase of treatment time. It showed that the interaction between the glow discharge plasma and the BOPP surface achieved a dynamic balance, the Ar/air plasma modification on the surface of BOPP film mainly occurred in 0 - $30 \mathrm{~s}$. Then even the plasma treatment time continued to increase, the water contact angle of the

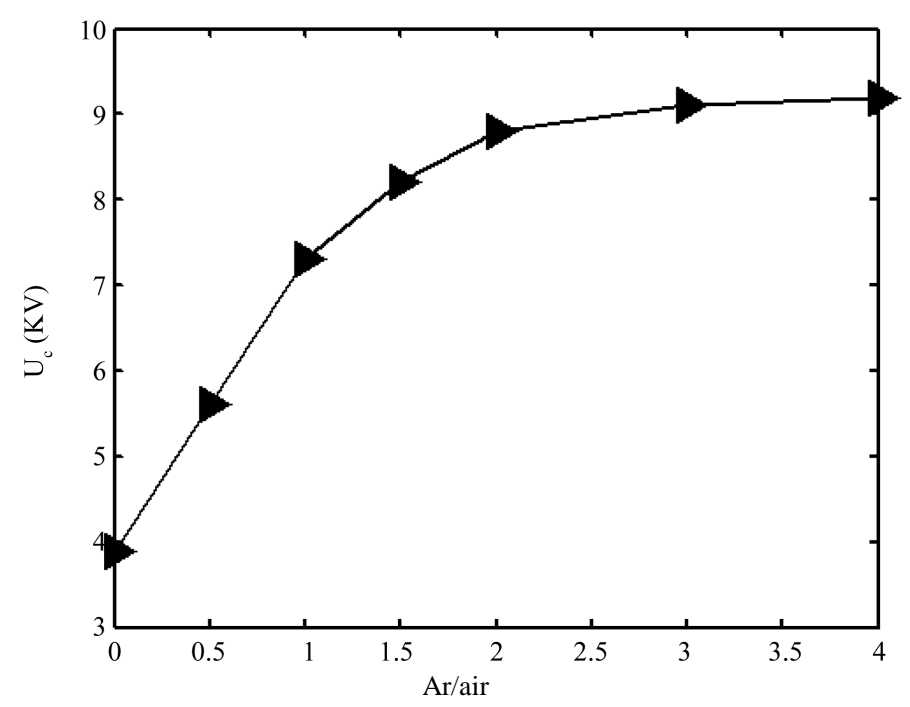

Figure 6. Dependence of the minimum glow discharge voltage versus the mixture ratio of Ar/air.

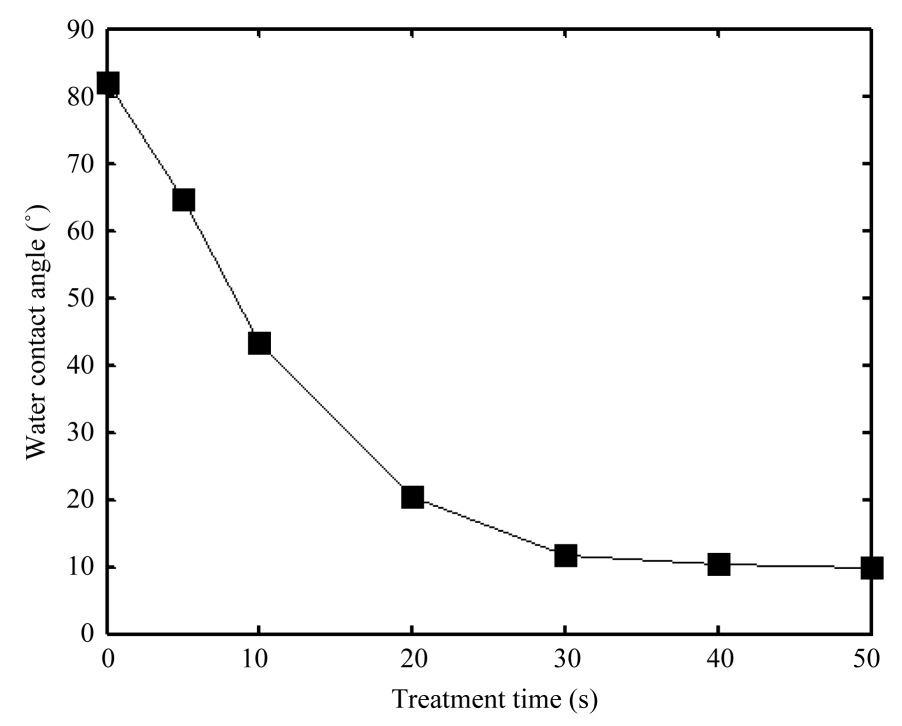

Figure 7. Changes of water contact angle with plasma treatment time. 
sample surface had little change.

Given in Figure 8 were the changes of water contact angle with discharge voltage, the treatment time is $20 \mathrm{~s}$. When the discharge voltage was less than $3.2 \mathrm{KV}$, the water contact angle decreases very little with the rise of discharge voltage. When the discharge voltage was larger than $3.2 \mathrm{KV}$, the water contact angle decreased rapidly with the increase of discharge voltage, when the discharge voltage was more than $10 \mathrm{KV}$, the water contact angle nearly did not change. It because the gas ionization degree was lower for lower applied voltage, the charged particles had little effect on the sample surface. When the applied voltage was greater than $3.2 \mathrm{KV}$, the gas ionization degree increased dramatically, charged particle played an increasing role on the surface modification. When the applied voltage was more than $10 \mathrm{KV}$, the discharge was in a stable glow discharge model, the gas ionization degree had little increase with the increase of the discharge voltage.

Figure 9 showed the changes of water contact angle with the ratio of $\mathrm{R}=\mathrm{Ar} / \mathrm{air}$. In the region $0 \leq \mathrm{R} \leq 1.5$, the mixture proportion of $\mathrm{Ar} /$ air increased, the atom mass of $\mathrm{Ar}$ is greater than the atom mass of $\mathrm{N}$ or $\mathrm{O}$. Therefore it was understandable that the water contact angle decreased with increase of the ratio of R. And the higher ratio of Ar/air made the better effects on the material surface modification. When the mixture ratio achieved 1.5, the water contact angle of the sample decreased to $18.4^{\circ}$. In the region $\mathrm{R}>1.5$, the water contact angle increased

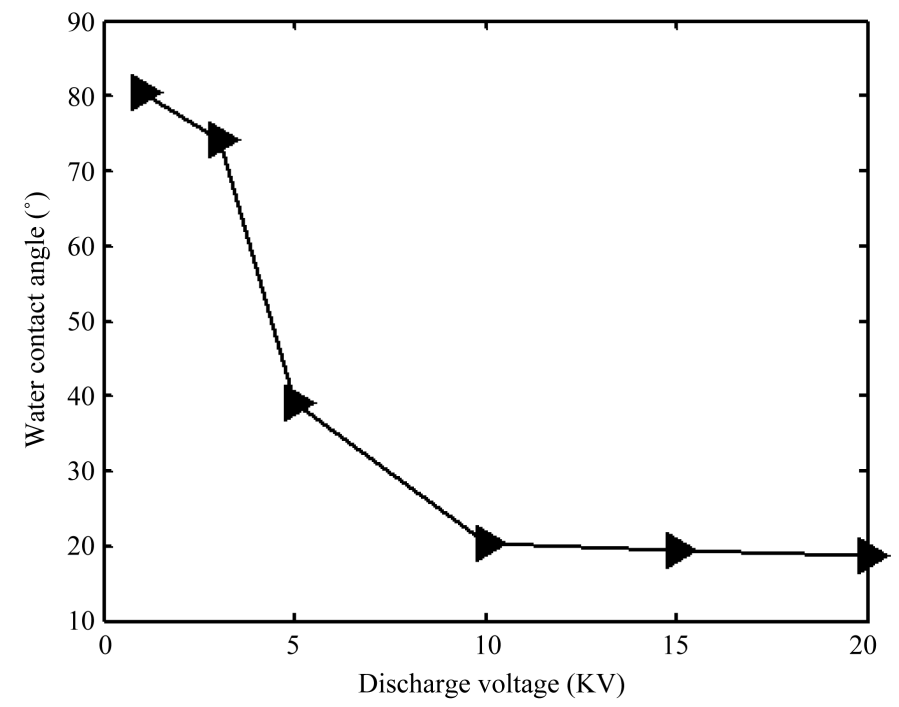

Figure 8. Changes of water contact angle with discharge voltage.

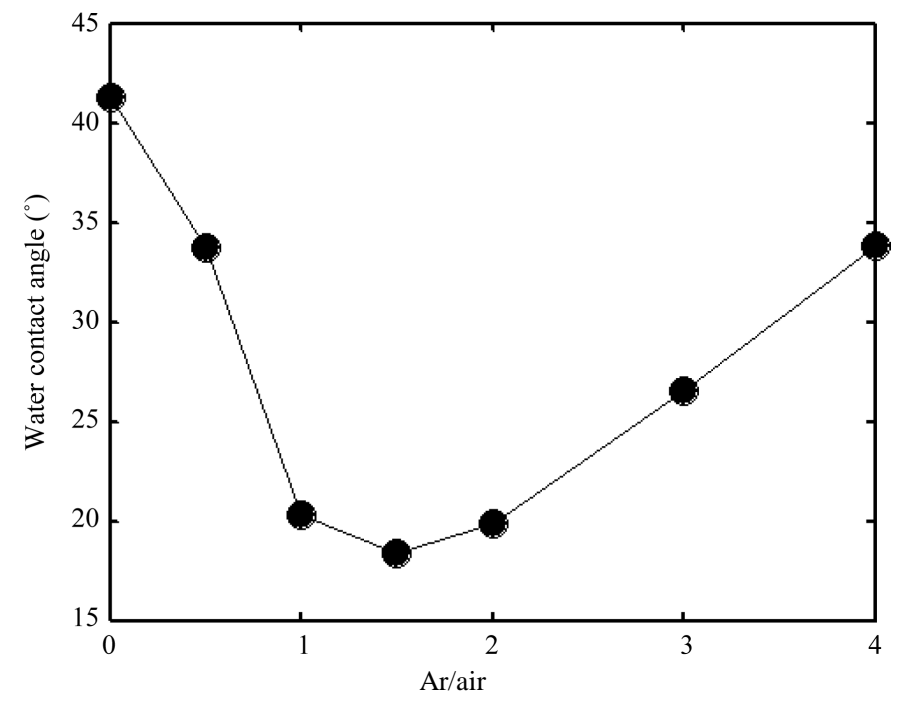

Figure 9. Changes of water contact angle with the ratio of Ar/air. 
with increase of the ratio $\mathrm{R}$. This because when the ratio of Ar/air increased to a critical value, the ionization degree of the discharge gas decreases, the glow discharge model may be converted to filamentary discharge model. It indicated that for Ar/air plasma, the glow discharge was better for improving the surface wettability of BOPP material than the filamentary discharge.

The chemical reaction in BOPP surface upon plasma treatment could be characterized by the FT-IR measurement. As illustrated in Figure 10, there were some differences between untreated and treated samples, some new peaks appeared and some peak intensities were increased in the treated BOPP films due to Ar/air plasma treatment. According to the figure, major changes appeared in the wave number range of $750 \mathrm{~cm}^{-1}-1500 \mathrm{~cm}^{-1}$ and $2500 \mathrm{~cm}^{-1}-3000 \mathrm{~cm}^{-1}$, some chemical reactions such as formation of C-H bonds occurred, and the intensity of many peaks increased.

The ageing process of plasma treated samples is an important factor to evaluate the efficiency of plasma modification on material surface. The ageing of hydrophilic is caused by the two following reasons [28]: 1) The treated material would absorb some small molecules in the air, so that the surface free energy and the hydrophilic decrease gradually. 2) The polar groups on the big molecular chain enter into the surface of the treated material with the rotation of big molecular chain. Figure 11 showed the ageing process of plasma treated samples stored in air, the treatment time was $20 \mathrm{~s}$. The water contact angle increased when the treated samples were

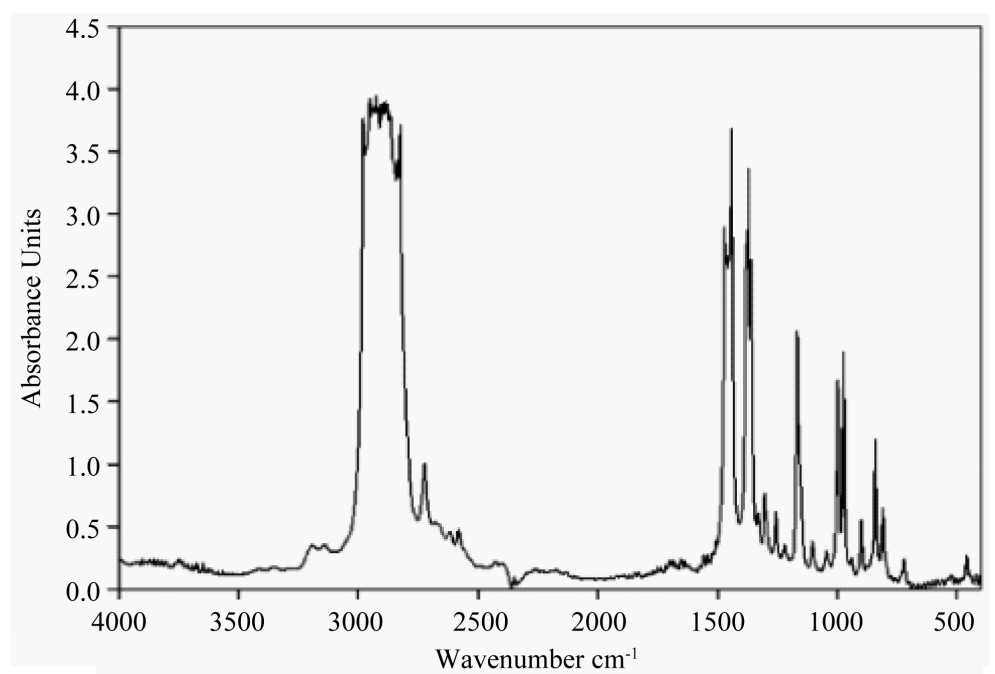

(a)

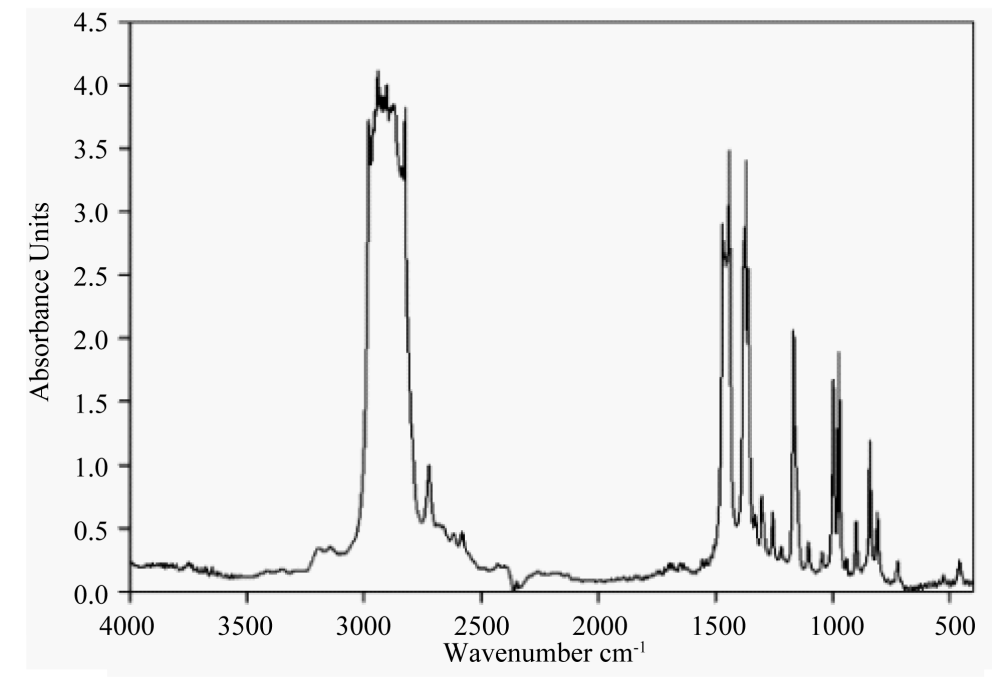

(b)

Figure 10. FT-IR spectra of Ar/air plasma untreated (a) and $30 \mathrm{~s}$ treated (b) BOPP films. 


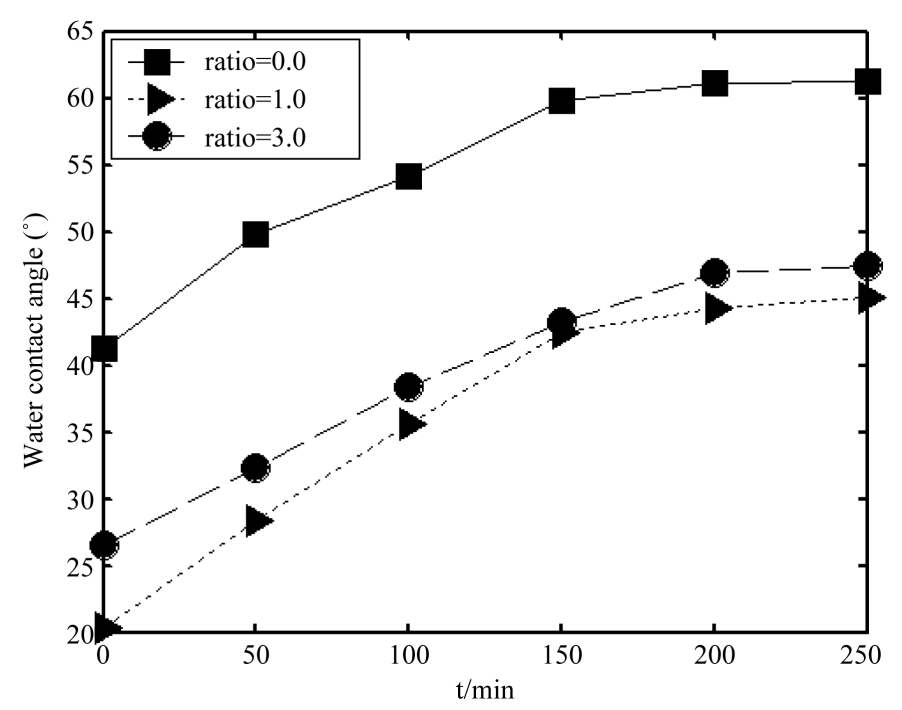

Figure 11. Time evolution of the water-contact angle of the modified BOPP membranes in storage in air.

stored in air, and the hydrophilic effect declined gradually. However, the water contact angle was always less than that of un-treated sample. The DBGD of Ar/air mixture gas on the surface modification of BOPP material had a good effect.

\section{Conclusion}

In this paper, the surface treatment of BOPP film by DBGD in Ar/air plasma was carried out. The DBGD discharge generated under atmospheric pressure could be used as the efficient technique for the BOPP surface modification, and DBGD gave better surface modification than filament discharge. The efficiency of the plasma modification increased with increasing treatment time and plasma power density. The interaction of the plasma discharge with the BOPP caused the decrease of the water angle and increase of the surface energy. The water contact angle increased, and then decreased with the increasing mixture rate of Ar/air. The ageing behavior was influenced by many factors for different mixture Ar/air plasma; however, the surface character of the treated sample was always better than un-treated sample.

\section{Acknowledgements}

This work is supported by the Natural Science Foundation of Shandong Province of China under Grant No. ZR2012AQ025 and the National Nature Science Foundation of China under Grant No. 11175156, and the Key Science Program Foundation of Shandong Youth University of Political Science under grant no. 2013ZD09.

\section{References}

[1] Nuntapichedkul, B., Tantayanon, S. and Laohhasurayotin, K. (2014) Applied Surface Science, 314, 331. http://dx.doi.org/10.1016/j.apsusc.2014.06.032

[2] Guimond, S., Radu, I., Czeremuszkin, G., et al. (2002) Plasmas and Polymers, 7, 71. http://dx.doi.org/10.1023/A:1015274118642

[3] Hamideh Mortazavi, S., Ghoranneviss, M., Pilehvar, S., et al. (2013) Plasma Science and Technology, 15, 362. http://dx.doi.org/10.1088/1009-0630/15/4/10

[4] Lin, Y.J., Dias, P., Chen, H.Y., et al. (2008) Polymer Engineering \& Science, 48, 642. http://dx.doi.org/10.1002/pen.20988

[5] Tamura, S., Takino, K., Yamada, T., et al. (2012) Journal of Applied Polymer Science, 126, E501. http://dx.doi.org/10.1002/app.36803

[6] Navaneetha Pandiyaraj, K., Selvarajan, V., Deshmukh, R.R., et al. (2009) Applied Surface Science, $255,3965$. http://dx.doi.org/10.1016/j.apsusc.2008.10.090 
[7] Yuan, X. and Mike Chung, T.C. (2011) Applied Physics Letters, 98, Article ID: 062901.

[8] Lin, Y., Hiltner, A. and Baer, E. (2010) Polymer, 51, 5807. http://dx.doi.org/10.1016/j.polymer.2010.09.070

[9] Lehocky, M., Drnovska, H., Lapcikova, B., et al. (2003) Colloids and Surfaces A: Physicochemical and Engineering Aspects, 222, 125. http://dx.doi.org/10.1016/S0927-7757(03)00242-5

[10] Zheng, B.C., Wang, K.S. and Lei, M.K. (2015) Plasma Science and Technology, 17, 309. http://dx.doi.org/10.1088/1009-0630/17/4/09

[11] Chu, P.K., Chen, J.Y., Wang, L.P. and Huang, N. (2002) Materials Science and Engineering: R: Reports, 36, $143-206$. http://dx.doi.org/10.1016/S0927-796X(02)00004-9

[12] Kostov, K.G., Nishime, T.M.C., Castro, A.H.R., Toth, A. and Hein, L.R.O. (2014) Applied Surface Science, 314, 367375. http://dx.doi.org/10.1016/j.apsusc.2014.07.009

[13] Shenton, M.J. and Stevens, G.C. (2001) Journal of Physics D: Applied Physics, 34, 2761-2768. http://dx.doi.org/10.1088/0022-3727/34/18/308

[14] Yousefi, R.H., Ghoranneviss, M., Tehrani, A.R. and Khamseh, S. (2003) Surface and Interface Analysis, 35, 10151017. http://dx.doi.org/10.1002/sia.1633

[15] Ring, A., Tilkorn, D.J., Goertz, O., Langer, S., Schaffran, A., Awakowicz, P. and Hauser, J. (2011) Journal of Orthopaedic Research, 29, 1237-1244. http://dx.doi.org/10.1002/jor.21358

[16] Pandiyaraj, K.N., Selvarajan, V., Deshmukh, R.R., Yoganand, P., Balasubramanian, S. and Maruthamuthu, S. (2013) Plasma Science and Technology, 15, 56-63. http://dx.doi.org/10.1088/1009-0630/15/1/10

[17] Zhou, L., Lü, G.H., Chen, W., et al. (2011) Chinese Physics B, 20, 329.

[18] Kostov, K.G., dos Santos, A.L.R., Nascente, P.A.P., Kayama, M.E., Mota, R.P. and Algatti, M.A. (2012) Journal of Applied Polymer Science, 125, 4121-4127. http://dx.doi.org/10.1002/app.35290

[19] Novák, I., Števiar, M., Popelka, A., Chodák, I., Mosnáček, J., Špírková, M., et al. (2013) Polymer Engineering and Science, 53, 516-523. http://dx.doi.org/10.1002/pen.23280

[20] Anand, V., Ghosh, S., Ghosh, M., Rao, G.M., Railkar, R. and Dighe, R.R. (2011) Applied Surface Science, 257, 83788384. http://dx.doi.org/10.1016/j.apsusc.2011.04.040

[21] Inagaki, N., Narushima, K., Tsutsui, Y. and Ohyama, Y. (2002) Journal of Adhesion Science and Technology, 16, 1041-1054. http://dx.doi.org/10.1163/156856102760146156

[22] Seo, E. (2002) Macromolecular Research, 10, 291-295. http://dx.doi.org/10.1007/BF03218321

[23] Yu, H.Y., He, X.C., Liu, L.Q., Gu, J.S. and Wei, X.W. (2007) Water Research, 41, 4703-4709. http://dx.doi.org/10.1016/j.watres.2007.06.039

[24] Pimanpang, S., Wang, P., Ye, D., Juneja, J.S., Wang, G.C. and Lu, T.M. (2007) Journal of the Electrochemical Society, 154, G215-G219. http://dx.doi.org/10.1149/1.2766606

[25] Wagner, A.J., Fairbrother, D.H. and Reniers, F. (2002) Plasma and Polymers, 8, 109.

[26] Zhou, J., Li, W., Gu, J. and Yu, H.Y. (2010) Membrane Water Treatment, 1, 83-92. http://dx.doi.org/10.12989/mwt.2010.1.1.083

[27] Švorčík, V., Kolářová, K., Slepička, P., Bláhová, O., Špírková, M., Sajdl, P. and Hnatowicz, V. (2006) Nuclear Instruments and Methods in Physics Research Section B: Beam Interactions with Materials and Atoms, 244, 365-372. http://dx.doi.org/10.1016/j.nimb.2005.10.003

[28] Cui, N.Y. and Brown, N.M.D. (2002) Applied Surface Science, 189, 31-38. http://dx.doi.org/10.1016/S0169-4332(01)01035-2 